\title{
Melting Behavior of Poly(ethylene oxide)-Polystyrene- Poly(ethylene oxide) Triblock Copolymer by Gas Chromatography
}

\author{
Kikuo Shoji, Kanehiro Nakamura, Ryuichi Endo, \\ and Masatami TAKEDA \\ Department of Chemistry, Faculty of Science, Science University of Tokyo, \\ Kagurazaka, Shinjuku-ku, Tokyo, Japan. \\ (Received December 22, 1975)

\begin{abstract}
KEY WORDS Triblock Copolymer / Preferential Solvent / FreezeDrying with Water / Freeze-Drying with Benzene/Gas Chromatography / Specific Retention Volume /
\end{abstract}

Recently, by using gas chromatography (GC), various kinds of information in the field of polymer science have been obtained, such as polymer-solute interactions, ${ }^{1-3}$ second-order transition temperatures, ${ }^{4}$ degrees of crystallinity, ${ }^{5,6}$ and the like.

In this work, we have studied the melting behavior of poly(ethylene oxide)-polystyrenepoly(ethylene oxide) (PEO-PS-PEO) triblock copolymer using two kinds of GC column fillers. These were prepared by a freeze-drying method with water as a preferential solvent of PEO blocks, and with benzene as a good solvent for blocks of both PEO and PS. We wish to report here some new and interesting preliminary results obtained with the triblock copolymer as a stationary phase liquid.

The triblock copolymer was prepared by anionic polymerization with potassium naphtharene under a high vacuum of $10^{-5} \mathrm{mmHg}$ in THF solvent at methanol-dry ice temperature. ${ }^{7}$

The number-average molecular weight of the copolymer was obtained in benzene solution at $37^{\circ} \mathrm{C}$ by using a vapor pressure osmometer (VPO) from Mechrolab, Model-302, and found to be 4800. The composition of this copolymer was determined by measuring NMR spectra using a Varian-A-60 spectrometer at $20^{\circ} \mathrm{C}$, and found to be 13.5 in monomer compositional ratio of PEO to PS.

The GC experiments were performed with a Yanagimoto GC, Yanaco-G8 Model, equipped with a thermal conductivity detector. The column was $4 \mathrm{~mm}$ od stainless steel tubing, 750 $\mathrm{mm}$ long. Helium was employed as a carrier gas and the flow rate was controlled at $40 \mathrm{ml} /$ min, as measured by a bubble flow meter. The support was Chromosorb-G, AW, DMCS (6080 mesh) which was heated for $5 \mathrm{hr}$ until a constant weight was reached. The copolymer was dissolved in water as a casting solvent, then the support was added in this solution. The column filler, which is covered with a thin film of the copolymer, was prepared by freeze-drying of the mixture under a vacuum of $10^{-3} \mathrm{mmHg}$ for 60 hr. By the same method, another column filler was obtained by mixing the support and the benzene solution. Accurate amounts of the copolymer deposited on the column filler were determined by thermal gravimetric analysis using one gram of the sample.

$n$-Decane (Tokyo Kasei 99\% up) was used as a solute without further purification. The solute was injected into the gas flow by using a $0.1 \mu l$ capacity micro syringe of "Precision Sampling."

A relative retention time was defined by the distance between the maxima of the air peak and the solute peak, by considering the hold-up in the column. A relative retention volume $(V r)$ was calculated from the relative retention time. It is well known that $V r$ depends significantly on the amount of injected solute. But $V r$ should be constant, due to Henry's law, in the case of infinite dilution. Since the peak height was proportional to the amount of injected solute, $V r$ at infinite dilution $(V \stackrel{\circ}{r})$ was obtained 
by extrapolating $V r$ to zero peak height. The value of $V^{\circ} r$ was reduced to the specific retention volume $\left(V_{g}^{\circ}\right)$, as defined in eq 1 ; this is illustrated in a key text ${ }^{8}$ and will not be discussed here.

$$
V \stackrel{\circ}{=}=\frac{273 V^{\circ}}{T W}
$$

Here $T$ is the column temperature $\left({ }^{\circ} \mathrm{K}\right), W$ is the weight of coated polymer in the column, and $V_{r}^{\circ}$ is the extrapolated retention volume at infinite dilution.

The column packed with the filler obtained from the water solution was coded as column$\mathrm{W}$, and column-B was packed with the filler obtained from benzene solution. The amounts of the copolymer in column-W and column-B were $0.1442 \mathrm{~g}$ and $0.1324 \mathrm{~g}$, respectively.

The value of $V \stackrel{\circ}{g}$ for $n$-decane was determined at a series of temperatures by using these columns. The data are plotted in a generalized retention diagram in the form of $\log V_{g}^{\circ}$ as a function of the reciprocal absolute temperature $(1 / T)$. Figure 1 shows such curves for column$\mathrm{W}$ and column-B.

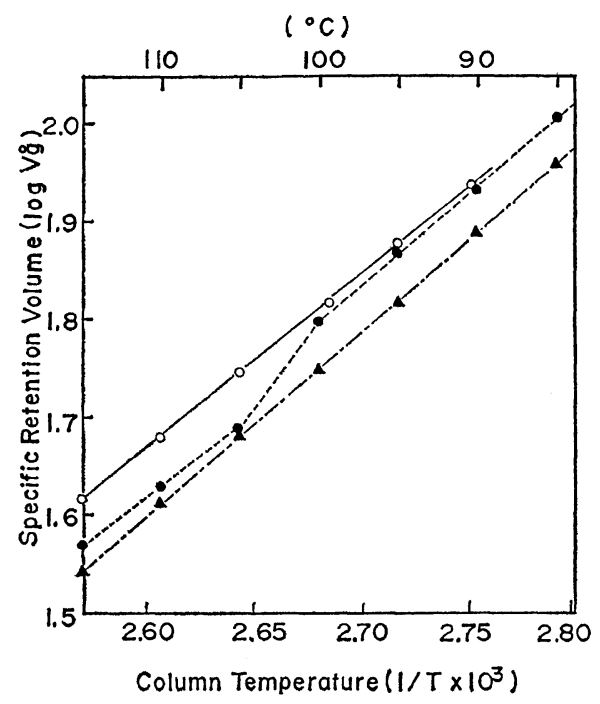

Figure 1. Dependence of specific retention volume on reciprocal of column temperature: Solute, $n$ decane; - - , column packed with PEG-4000; -- - column-W (prepared by freeze drying with water; - - - - , column-B (prepared by freeze drying with benzene).
The homopolymer of poly(ethylene glycol) (PEG-4000) was used as a stationary phase for comparison with the triblock copolymer. The number-average molecular weight of PEG-4000 was found to be 3800 , by using VPO in benzene solution at $37^{\circ} \mathrm{C}$. The results obtained with this PEG-column are also shown in Figure 1.

PEG-column and column-B yield straight lines over the entire temperature range for $n$-decane. But column-W shows a different behavior: the curve almost coincides with that of PEG-column at the temperatures below $100^{\circ} \mathrm{C}$, whereas it approaches the curve of column-B above $105^{\circ} \mathrm{C}$. An ablupt change is observed in the curve of column-W. Since no fluctuation of the base line in the GC was observed at all around $105^{\circ} \mathrm{C}$, it is difficult to believe that this abrupt change is caused by elution of some adsorbed water of the casting solvent from the column.

Gervais, et al., ${ }^{9}$ studied the liquid-crystalline structures of PEO-PS block copolymer in the preferential solvent for one of the blocks by using small angle X-ray scattering and differential scanning calorimetry; they found two liquidcrystalline structures, L. C. and L. L. Both of these were lamella, but they differed in the state of the PEO block. Skoulios, et al., ${ }^{10}$ reported that the microphase separation of PEO-PS block copolymer occurred in the solvent-copolymer system, and that the state of this mesophase depends on the nature of the preferential solvent. In connection with these reports, it is considered that the melting behavior of PEO-PS-PEO triblock copolymer shown in the retention diagram might be connected with the results of PEO_PS block copolymer reported by Gervais, et al. and Skoulios, et al.

\section{REFERENCES}

1. O. Smidsrød and J. E. Guillet, Macromolecules, 2, 272 (1969).

2. F. H. Covitz and J. W. King, J. Polym. Sci., 10, 689 (1972).

3. K. Shoji and M. Takeda, Kobushi Ronbunshu, (Chem. High Polymers), 31, 7 (1974).

4. A. Lavoie and J.E. Guillet Macromolecules, 2, 443 (1969)'

5. J. E. Guillet and A. N. Stein, ibid., 3, 102 (1970). 


\section{Melting Behavior of Triblock Copolymer}

6. K. Shoji, M. Yayoshi, and M. Takeda, Kobunshi Ronbunshu (Chem. High Polymers), 32, 9 (1975).

7. K. Nakamura, R. Endo, and M. Takeda, $J$. Polym. Sci., 13, 12 (1975).

8. A. B. Littlewood, "Gas Chromatography",
Academic Press, New York, N.Y., (1962).

9. M. Gervais, A. Douy, and B. Gallot, Mol. Cryst. and Liq. Cryst., 13, 284 (1971).

10. A. Skoulios and G. Finaz, J. Chim. Phys., 59, 473 (1962). 